\title{
GLUTAMATE SIGNALLING AND ITS POTENTIAL APPLICATION TO TISSUE ENGINEERING OF BONE
}

\author{
Deborah J. Mason* \\ School of Biosciences, Cardiff University, Museum Avenue, \\ Cardiff, CF10 3US, U.K.
}

\begin{abstract}
Mechanical loading of the skeleton is important for maintenance of adequate bone mass and defined mechanical stimuli are highly osteogenic. The identification of mechanoresponsive signalling molecules in bone may allow osteogenic signals to be mimicked. This approach would be useful in the treatment of bone pathologies where the skeleton is too weak to withstand osteogenic forces and to tissue engineering of bone where the mechanical environment of bone cells is disrupted. Glutamate has been implicated as a mediator of mechanical signalling in bone. Evidence for glutamate signalling in bone, its role in mechanotransduction and potential applications of this pathway to tissue engineering of bone is considered in this review. Glutamate receptors, transporters and proteins that regulate glutamate release, are all expressed in bone cells. Glutamate receptor activation affects both osteoblast and osteoclast phenotypes revealing a potential for therapeutic manipulation of glutamate signalling to enhance bone formation. Glutamate transporters contribute to this system by regulating extracellular glutamate concentrations and acting as glutamate-gated ion channels. Artificial regulation of glutamate receptors or transporters may be used to increase the bone forming capacity of osteoblasts. This novel approach may potentially enhance bone tissue engineering strategies.
\end{abstract}

Key Words: Glutamate, bone tissue engineering, glutamate transporters, glutamate receptors, osteocytes, osteoblasts, osteoclasts, ion channels, mechanical load.

*Address for correspondence:

Deborah J. Mason

School of Biosciences,

Cardiff University,

Museum Avenue,

Cardiff, CF10 3US, U.K.

E-mail:masondj@cardiff.ac.uk

\section{Introduction}

The excitatory amino acid glutamate was first implicated in bone cell signalling when a glutamate transporter was identified in a gene screening experiment designed to reveal genes involved in osteogenic signalling (Mason et al., 1997). Shortly after this, other workers reported the expression of glutamate receptors in bone cells (Chenu et al., 1998; Patton et al., 1998) and the close association of bone cells with glutamatergic nerve endings (Serre $e t$ al., 1999). Since then all the components required for a functional glutamate signalling system have been demonstrated to be expressed in bone cells. In addition both metabotropic and ionotropic glutamate receptors have been shown to be functional in osteoblasts (Laketic-Ljubojevic et al., 1999; Gu et al., 2002) and osteoclasts (Epsinosa et al., 1999; Peet et al., 1999) and antagonists to these receptors have been demonstrated to modify the phenotype of bone cells at least in in vitro assays (Chenu et al., 1998, Peet et al., 1999; Izstein et al., 2000; Gu and Publicover, 2000; Gray et al., 2001 a,b; Skerry and Genever, 2001; Taylor, 2002; Merle et al., 2003). Whilst the significance of glutamate signalling in bone in vivo is not fully understood, the regulation of glutamate transporters in response to mechanical loading in vivo has implicated glutamate signalling either in the transmission of mechanical stimuli in osteocytes, or in the response of these cells to their mechanical environment.

It is well established that mechanical loading is a critical factor in the maintenance of adequate bone mass in the skeleton. Furthermore, increases in the forces applied to particular areas of the skeleton will cause a physiological adaptation to increase the bone mass and thus the strength at that particular site. In many circumstances where skeletal defects occur, and where bone tissue engineering may be applied (fracture, microfracture, prosthesis failure), the mechanical integrity of the bone has become compromised which may lead to abnormal detection and/or transduction of mechanical stimuli by bone cells. This paper briefly reviews current evidence for glutamate signalling in bone and discusses whether artificial modulation of glutamate signalling may ultimately be used to mimic the osteogenic potential of mechanical stimulation. The role of glutamate/ aspartate transporter 1 (GLAST-1) in osteogenic signalling and its potential as a target to modulate glutamate signalling will be investigated in more detail. Pharmacological manipulation of glutamate receptors or transporters in bone cells may enable us to bypass the need for their mechanical stimulation when embedded in weak or disorganised matrix and enhance the success of bone tissue engineering strategies. 


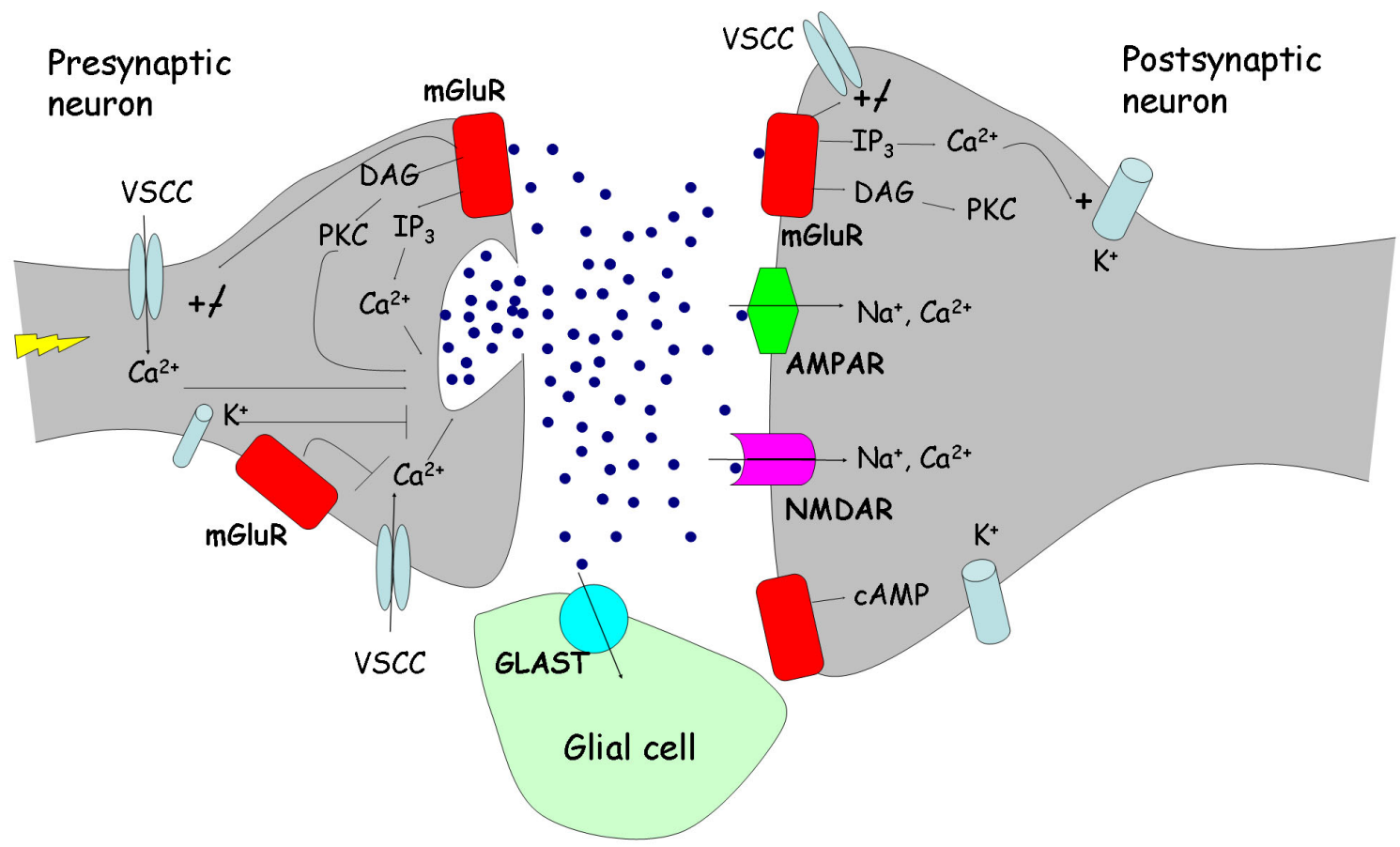

Figure 1. Glutamate signalling in the CNS. Upon excitation of the pre-synaptic neuron, $\mathrm{Ca}^{2+}$ influx through voltage sensitive calcium channels (VSCC) causes glutamate release into the synaptic cleft from synaptic vesicles by calciumdependent exocytosis. Binding of glutamate to metabotropic glutamate receptors (mGluR) can either potentiate or inhibit glutamate release. Released glutamate binds to ionotropic (NMDAR, AMPAR) or metabotropic receptors (mGluR) expressed on the post-synaptic neuron causing $\mathrm{Na}^{+}$and $\mathrm{Ca}^{2+}$ influx and activating G-protein coupled signalling pathways. Glutamate released into the synpase is quickly bound by transporters such as GLAST-1 expressed on glial cells and neurons causing uptake of glutamate and termination of the excitatory signal. Glutamate is converted to glutamine and either used metabolically or recycled for subsequent release. Diacylglycerol (DAG), protein kinase $\mathrm{C}$ (PKC), inositol triphosphate (IP3), cyclic adenosine monophosphate (cAMP).

\section{The Identification of Mechanically Regulated Signals}

There is much evidence that mechanical stimulation increases bone formation in vivo. Whereas disuse or immobilisation of a limb causes bone loss, very short periods of high frequency loads can prevent this loss and even induce bone formation (Rubin and Lanyon, 1987; Pead et al., 1988a). There are three types of cell within bone, osteoblasts that synthesise bone matrix, osteoclasts that resorb the bone and osteocytes that are distributed throughout the bone matrix, intercommunicating with each other and cells at the bone surfaces. Osteocytes are ideally situated for mechanical signal transduction and have been demonstrated to respond to short periods of load in vivo by increasing transcriptional and metabolic activity (Pead et al., 1988b; Skerry et al., 1989). Investigations of the mechanical loading parameters most likely to produce an osteogenic effect (reviewed in Skerry, 1997; Burr et al., 2002) have shown that high strain rates and short periods of loading are all that is required to elicit maximal osteogenic responses. The specific requirements of mechanical signalling in bone are well matched to the properties of glutamate signal transduction (Skerry, 2002; Turner et al., 2002; Spencer and Genever, 2003). The glutamate signalling apparatus has both the potential to detect very fast signals (and thus differences in strain rates) and the ability to self modify or have a 'memory' of previous signalling episodes so that maximal responses are achieved by relatively few signalling events. Glutamate receptors and transporters, capable of activation within these timescales, are expressed by bone cells as are proteins capable of modifying receptor activation based upon previous glutamate signals.

We set out to identify mechanoresponsive genes that may ultimately be manipulated to mimic the osteogenic signal that results from mechanical stimulation (Mason et al., 1997). An established in vivo model of mechanical loading was used where a non-invasive force $(10 \mathrm{~N}, 10 \mathrm{~Hz}, 10$ minutes) was applied to the rat ulna. This had previously been demonstrated to elicit increased bone formation on the dorso-medial surface of the ulna when compared to the contra-lateral control limb (Torrance et al., 1994; Hillam and Skerry, 1995). RNA fingerprints generated from osteocytes immediately underlying the responsive surface were compared between loaded and control bones by differential RNA display. One gene that was constitutively expressed by the osteocytes in control bone, but absent in the loaded limb, was cloned and found to encode GLAST1. GLAST-1 is a glutamate/aspartate transporter that had previously been associated exclusively with the central nervous system (CNS). The human homologue of the rat GLAST-1 gene is called excitatory amino acid transporter (EAAT) 1. This led us to the notion that glutamate may be 
involved with mechanical signal transduction in bone. This idea has been supported by a wealth of evidence revealing that glutamate receptors are expressed and functional in bone cells and their activation can modulate bone cell phenotype.

\section{Evidence for Glutamate Signalling in Bone}

Glutamate is the major mediator of excitatory signals in the CNS and knowledge of this system has guided research in bone. A simplified overview of glutamate-mediated signalling in the CNS is given in figure 1. Upon excitation of a neuron, voltage dependent $\mathrm{Ca}^{2+}$ channels (VSCC) are activated and the resultant $\mathrm{Ca}^{2+}$ influx causes glutamate release by exocytosis. In this process, $\mathrm{Ca}^{2+}$ binds to protein complexes associated with primed synaptic vesicles tethered to the presynaptic membrane by docking proteins. Fusion of synaptic vesicles with the presynaptic membrane releases glutamate into the synaptic cleft. Glutamate release is terminated by the opening of $\mathrm{K}^{+}$channels and inhibitory effects of some classes of metabotropic glutamate receptors (mGluRs) on VSCCs. Released glutamate activates various classes of glutamate receptor on the post-synaptic membrane. Ionotropic glutamate receptors act as glutamate gated ion channels and their activation causes $\mathrm{Ca}^{2+}$ influx. Metabotropic glutamate receptors are G-protein coupled and either activate phospholipase $\mathrm{C}$ production of diacylglycerol or inositol triphosphate, or are negatively linked to adenylate cyclase. Glutamate transporters, present both on the neuronal and glial cells, quickly bind released glutamate and terminate the excitatory signal. The glutamate transporters mediate glutamate uptake into the cell where it is converted to glutamine by glutamine synthetase and either used for metabolic purposes or recycled for subsequent neurotransmission. Thus there are four major components of glutamate signalling required for effective synaptic transmission: calcium activated release, receptor activation, signal propagation and signal termination. Proteins involved in all of these processes have been investigated in bone cells as summarised below.

\section{Glutamate Release}

The mechanisms for glutamate release in osteoblasts have been recently reviewed by Bhangu (2003). Osteoblasts constitutively release glutamate when cultured in vitro and this release appears to be regulated by voltage-dependent calcium entry (Genever and Skerry, 2001; Hinoi et al., 2002a). In neurons, depolarisation of the membrane potential induces calcium influx and release of glutamate by exocytosis. Depolarisation and agonists for ionotropic glutamate receptors have been shown to increase glutamate release in primary calvarial rat osteoblasts (Hinoi et al., 2002a). However, others report that depolarisation inhibits glutamate release in the osteoblast cell lines MG63 and SaOS-2 and does not affect glutamate release by a murine calvarial derived cell line (Genever and Skerry, 2001). Since glutamate release varies with differentiation of osteoblasts (Bhangu et al., 2001), the discrepancy in these responses may reflect the different phenotypes of the osteoblast-like cells used. In the CNS each signalling episode is started by an action potential and it is difficult to define an equivalent activator in bone. However, later in this review a model is proposed where mechanically- induced opening of stretch activated calcium channels in osteocytes may lead to glutamate release.

Osteoblasts express proteins that in the CNS have been associated with the glutamate vesicle fusion, docking to the plasma membrane and calcium-dependent glutamate release as shown in Table 1 (Barry, 2000; Bhangu et al., 2001; Banghu, 2003). In addition, electron microscope images of vesicles docking, fusing and apparently undergoing exocytosis in osteoblast-like MG63 cells is consistent with synaptic vesicle morphology in the CNS (Banghu, 2003). Whilst many of these components may be associated with constitutive rather than regulated exocytosis, the glutamate vesicle docking proteins and proteins specifically involved with calcium-dependent glutamate release (Rab3A and Synaptotagmin I) reveal the potential for fast, regulated, calcium-driven glutamate release mechanisms in osteoblasts (Bhangu, 2003). Interestingly osteocyte-like MLO-Y4 cells do not constitutively release glutamate when cultured under normal conditions (Genever and Skerry, 2001); whether glutamate release can be induced in these cells in response to mechanical loading is yet to be determined. To date, there are no reports of glutamate release by osteoclasts.

\section{Glutamate Receptors}

There are two classes of glutamate receptor in the CNS; the ionotropic receptors that act as glutamate gated ion channels and the metabotropic receptors which are G-protein coupled and activate either cyclic adenosine monophosphate (cAMP), inositol triphosphate $\left(\mathrm{IP}_{3}\right)$ or diacylglycerol (DAG) pathways. Ionotropic receptors are categorised according to the compounds that selectively activate them (N-methyl-D-aspartate (NMDA), a-amino3-hydroxy-5-methyl-4-isoxazole propionic acid (AMPA) and Kainate (KA)). Ionotropic receptors are often further categorised as NMDA and non-NMDA (AMPA and KA) since it is difficult to discriminate between AMPA and KA receptor activity. Various ionotropic receptor subunits are expressed in osteoblasts (Patton et al., 1998; Hinoi et al., 2002b) and osteoclasts (Itzstein et al., 2001; Chenu, 2002; Merle et al., 2003) as shown in Table 1. Electrophysiological studies of primary bone cells and bone cell lines have revealed that NMDA receptors are functional in both osteoblasts (Laketic-Ljubojevic et al., 1999; Gu et al., 2002) and osteoclasts (Epsinosa et al., 1999; Peet et al., 1999) and exhibit similar electrophysiological and pharmacological properties to their counterparts in neurons. Signalling proteins that are associated with the clustering of, and cross-talk between, glutamate receptors in the CNS are also expressed in osteoblasts (Patton et al., 1998; Skerry, 2002; Taylor, 2002).

There are eight different types of metabotropic receptor (mGluR) and to date mGluR 1, 4 and 8 have been reported to be expressed in osteoblasts $(\mathrm{Gu}$ and Publicover, 2000; Hinoi et al., 2001) (Table 1). In addition, these receptors have been demonstrated to be functional and to modulate activation of NMDA receptors in osteoblasts (Gu and Publicover, 2000). 


\begin{tabular}{|c|c|c|c|c|c|}
\hline \multicolumn{2}{|c|}{ Glutamate release by exocytosis } & \multicolumn{2}{|c|}{ Glutamate receptors } & \multicolumn{2}{|c|}{ Glutamate transporters } \\
\hline $\begin{array}{l}\text { Vesicle docking } \\
\text { Munc-18 } \\
\text { DOC2 } \\
\text { RSec8 } \\
\text { Synaptophysin } \\
\text { Regulatory } \\
\text { proteins } \\
\text { Rab3A,B,D } \\
\text { Rab3A,C } \\
\text { Synapsin } 1 \\
\text { SynaptogaminI } \\
\text { Ca }{ }^{2+} \text { dependent } \\
\text { glutamate } \\
\text { release } \\
\text { N \& P/Q type } \\
\text { calcium channels }\end{array}$ & $\begin{array}{l}\text { MG63, SaOS-2, TE85 } \\
\text { MG63,SaOS-2(1), } \\
\text { osteoblasts in vivo (2) } \\
\text { MG63,SaOS-2(1) } \\
\text { SaOS-2,MG63 (1) } \\
\\
\text { MG63,SaOS-2 \& } \\
\text { primary } \\
\text { osteoblasts(1) } \\
\text { MG63,SaOS-2(1) } \\
\text { MG63,SaOS-2(1) } \\
\text { MG63,SaOS-2(1) }\end{array}$ & $\begin{array}{r}\text { NMDAR2A } \\
\text { \& B } \\
\text { NMDAR2D } \\
\text { AMPA } \\
\text { GluR1 } \\
\text { GluR2 } \\
\text { GluR3 } \\
\text { KA } \\
\text { KA1 } \\
\text { KA2 } \\
\text { mGluR8 } \\
\text { Mroup III } \\
\text { mGluR4 } \\
\text { Mroup I } \\
\text { mGluR1b }\end{array}$ & $\begin{array}{l}\text { Osteoclasts, } \\
\text { osteoblasts,osteocytes in } \\
\text { vivo (5). MG63 }(5,6) \\
\text { SaOS-2 }(6) \text {. Cultured } \\
\text { osteoclasts }(5) \text {. Bone } \\
\text { marrow }(6,9) \text {. Primary } \\
\text { osteoblasts }(7,10) \\
\text { RAW264.7 cells (9) } \\
\text { Bone marrow (9). } \\
\text { RAW264.7 cells (9) } \\
\text { Bone marrow (6,9) } \\
\text { osteoclasts }(11) \text { Primary } \\
\text { osteoblasts }(7,10) \\
\text { RAW264.7 cells }(9) \\
\text { osteoclasts }(11) \\
\text { Primary osteoblasts }(7) \\
\text { Primary osteoblasts (7) } \\
\text { Osteocytes,osteoblasts in } \\
\text { vivo (5) } \\
\text { Osteocytes,osteoblasts in } \\
\text { vivo (5) } \\
\text { Primary calvarial } \\
\text { osteoblasts }(10) \\
\text { Primary calv osteoblasts } \\
\text { Primary calv osteoblasts } \\
\text { (10) }\end{array}$ & $\begin{array}{l}\text { GLT-1 } \\
\text { (EAAT-2) }\end{array}$ & $\begin{array}{l}\text { Osteocytes } \\
\text { and bone } \\
\text { forming } \\
\text { osteoblasts in } \\
\text { vivo }(12) \text {. } \\
\text { Primary } \\
\text { osteoblasts } \\
\text { and MLO-Y4 } \\
\text { and SaOS-2 } \\
\text { cells }(13,14) \text {. }\end{array}$ \\
\hline
\end{tabular}

Key (1) Bhangu et al. 2001, (2) Bhangu 2003, (3) Barry 2000, (4) Abu-Amer et al. 1999, (5) Chenu et al. 1998, (6) Patton et al. 1998, (7) Hinoi et al. 2001, (8) Gu and Publicover 2000, (9) Merle et al. 2003, (10) Hinoi et al. 2002b, (11) Izstein et al. 2001, (12) Mason et al. 1997, (13) Mason and Huggett 2002, (14) Huggett et al. 2002, (15) Huggett et al. 2000.

Table 1 Expression of glutamate signalling apparatus in bone cells

\section{Signal Propagation}

Activation of ionotropic receptors on osteoblasts causes membrane depolarisation and calcium influx (LaketicLjubojevic et al., 1999) leading to glutamate release and activation of secondary signalling pathways. These secondary pathways have not been characterised in osteoblasts although activation of receptor associated protein kinases and translocation of the transcription factor AP-1 has been re- ported (Taylor, 2002). However, the phenotypic effects of inhibition of receptor activation have been investigated more thoroughly. Thus in vitro assays have revealed that ionotropic glutamate receptor antagonists inhibit bone formation, inhibit osteoblast differentiation and reduce expression of bone matrix proteins (Skerry and Genever, 2001; Taylor, 2002; Hinoi et al., 2003). These effects may be mediated by $C b f a I$ as this transcription factor is also downregulated in osteoblasts by NMDA receptor antagonists 
(Hinoi et al., 2003). Thus activation of NMDA receptors appears to be important for the mature osteoblast, 'boneforming' phenotype.

Non-NMDA receptor antagonists have also been reported to influence osteoblast phenotype and these effects are dose dependent. Thus high doses of non-NMDA receptor antagonists inhibit bone formation in vitro whereas lower doses appear to increase bone formation (Skerry and Genever, 2001; Taylor, 2002). These different effects may be due to the different responses of AMPA and KA receptors (Taylor, 2002). It has also been proposed that non-NMDA receptor antagonists may influence commitment between osteoblast and adipocyte differentiation pathways (Skerry and Genever, 2001; Taylor, 2002).

NMDA receptor antagonists also affect osteoclast phenotype and have been reported to inhibit resorption pit formation (Izstein et al., 2000; Gray et al., 2001a,b) and osteoclast differentiation (Peet et al., 1999; Merle et al., 2003 ) in vitro. The effects of NMDA receptor antagonists on osteoclasts appear to vary with culture conditions. Some workers have attributed the major effect to be on osteoclast differentiation whereas others believe that effects on osteoclast activity are more important (see Chenu, 2002, for discussion). The involvement of the transcription factor, NFkB, in NMDA receptor signalling has recently been demonstrated in osteoclasts (Merle et al., 2003).

Binding of glutamate to metabotropic receptors activates G-protein coupled signalling pathways. These signalling pathways have not been investigated in bone cells to date but activation of metabotropic receptors has been shown to inhibit NMDA receptor activation in cultured osteoblasts (Gu and Publicover, 2000). This is consistent with 'cross-talk' between glutamate receptors in the CNS where activation of metabotropic receptors can modify ionotropic receptor activation. Such mechanisms represent potential means for very subtle and specific manipulation of glutamate signalling in bone cells. Importantly this crosstalk does not occur in osteoclasts revealing that the glutamate-induced signalling pathways are different in these two cell types and could therefore be modulated independently when both cell types are present.

\section{Signal Termination}

There are five high affinity $\mathrm{Na}^{+}$-dependant glutamate transporters (also referred to as sodium and potassium coupled glutamate transporters or excitatory amino acid transporters (EAATs) that have been implicated in termination of glutamate signalling in the synapse. These transporters are distinct from other glutamate transporters in the plasma membrane (glutamate exchangers with cystine, ascorbate, GABA or glycine) and intracellular transporters in mitochondria (proton -glutamate symporter and glutamate-aspartate antiporter) and those involved with glutamate uptake in synaptic vesicles (VGLUT1). Of the sodium-dependent transporters, only two have been found to be expressed in bone in vivo, GLAST-1 (EAAT1) and GLT-1 (EAAT2) (Mason et al., 1997). GLAST-1 is constitutively expressed by osteocytes whereas GLT-1 localises to mononuclear cells in the bone marrow in vivo. GLAST-1 expression also lo- calises to bone forming osteoblasts and is inhibited in osteocytes by mechanical loading. In addition, we have detected GLAST-1 mRNA expression in human primary chondrocytes, synoviocytes (Flood, Mason and Duance, unpublished data) and osteoblasts, the osteoblast-like cell line SaOS-2 and the osteocyte-like cell line MLO-Y4 (Huggett et al., 2000; Mason and Huggett, 2002; Huggett et al., 2002). The function of GLAST-1 in bone is considered in more detail below.

The evidence cited above shows that all components necessary for functional glutamate signalling are expressed in bone. Osteoblasts release glutamate in a regulated manner and express functional glutamate receptors. The activation of these glutamate receptors influences both osteoblast and osteoclast differentiation and activity. We have been investigating the role of GLAST-1 in this signalling mechanism in osteocytes and osteoblasts to determine how it may be regulated to enhance bone formation.

\section{What is the Function of GLAST-1 in Bone?}

\section{Structure of GLAST variants}

Since the mRNA encoding GLAST-1 expressed in bone is identical to that expressed in brain and the protein monomers are the same molecular weight in both tissues, we have proposed that this transporter may function similarly in bone and glial cells (Huggett et al., 2000; Mason and Huggett, 2002). We have also discovered that a splice variant of this gene, GLAST-1a, is expressed at low levels in brain and bone in vivo (Huggett et al., 2000) but is constitutively expressed at higher levels in MLO-Y4 osteocytes possibly reflecting a greater importance of this variant in these cells (Huggett et al., 2002).

The N-terminal part of GLAST-1 consists of 6 transmembrane (TM) alpha helices although the structure C-terminal to TM 6 is less clear. The structure shown in figure 2a for GLAST-1 follows Grunewald and Kanners (2000) model although other topologies have been proposed. Despite this controversy, all studies agree that $\mathrm{N}$ - and C- terminal sequences are intracellular. GLAST-1a differs to GLAST-1 by the excision of exon 3 encoding 46 amino acids comprising parts of the first two TM domains and the intervening sequence. We have proposed that the remnants of TM domains 1 and 3 fuse to form a new TM domain in GLAST-1a with the remainder of the protein being reoriented within the plasma membrane resulting in an extracellular C-terminal (Huggett et al., 2000, figure 2b). If GLAST-1a encodes an active transporter and is reoriented in the plasma membrane, it is likely to have different functional properties to GLAST-1.

\section{Function of GLAST variants}

GLAST-1 has many activities that may influence the phenotype of osteoblasts and to which GLAST-1a may contribute (figure 3). These activities include glutamate uptake, glutamate release, glutamate-gated ion channel activity and activation of intracellular signalling pathways. Glutamate uptake by GLAST-1 is driven by electrochemical gradients of sodium and potassium across the plasma membrane (Klockner et al., 1993; figure 3a). Thus glutamate is 
(a) GLAST-1

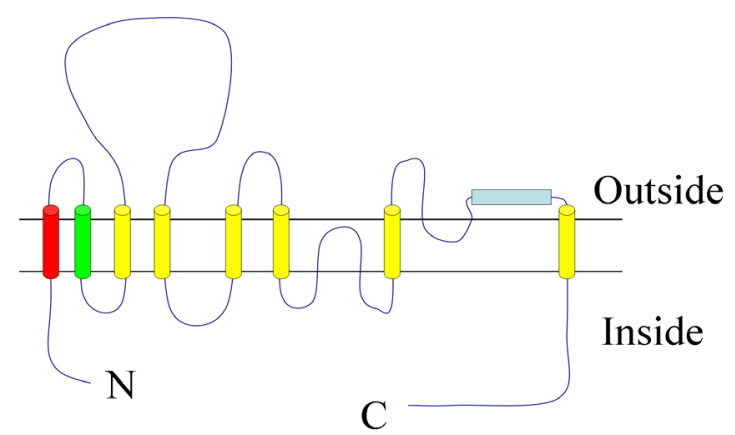

(b) GLAST-1a

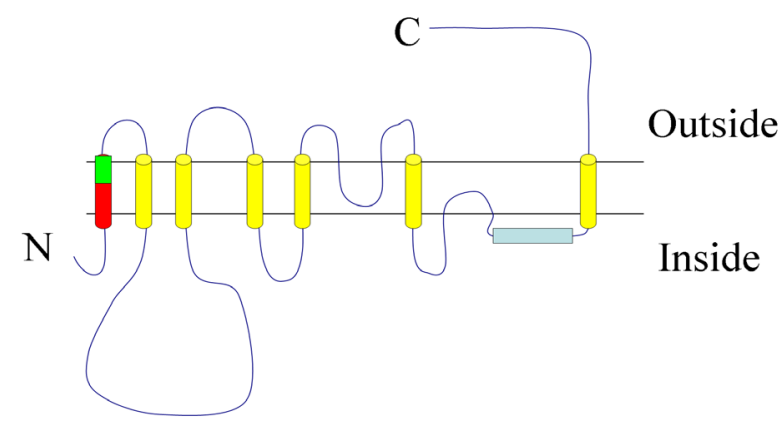

Figure 2. GLAST -1 and GLAST-1 a structure. (a) All proposed models for GLAST-1 structure reveal an intracellular N-terminal followed by 6 transmembrane (TM) domains and an intracellular C-terminal. The structure between TM domain 6 and the $\mathrm{C}$-terminal is less clear and the model proposed by Grunewald and Kanner (2000) is adopted here. Parts of the first two TM domains (red and green) and the intervening extracellular loop are encoded by exon 3 and therefore absent in the GLAST-1a splice variant. (b) We have proposed that loss of exon 3 would result in a new TM domain 1 and reorientation of the remainder of the protein in the plasma membrane (Huggett et al., 2000). (a) GLAST-1 glutamate transport activity

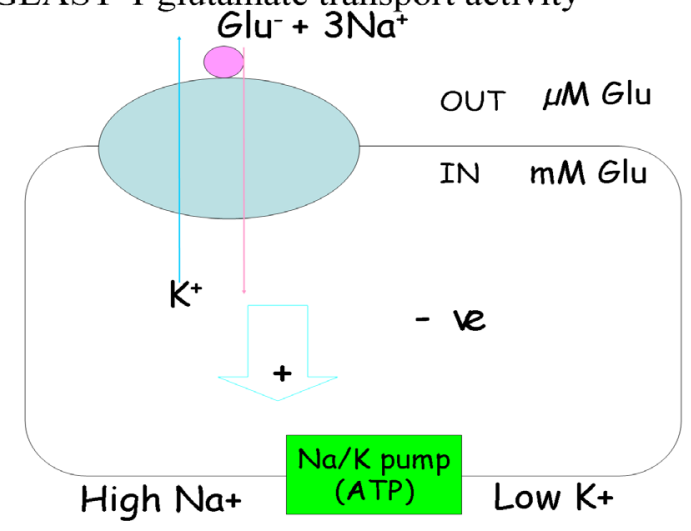

(b) GLAST-1 glutamate-gated ion channel activity

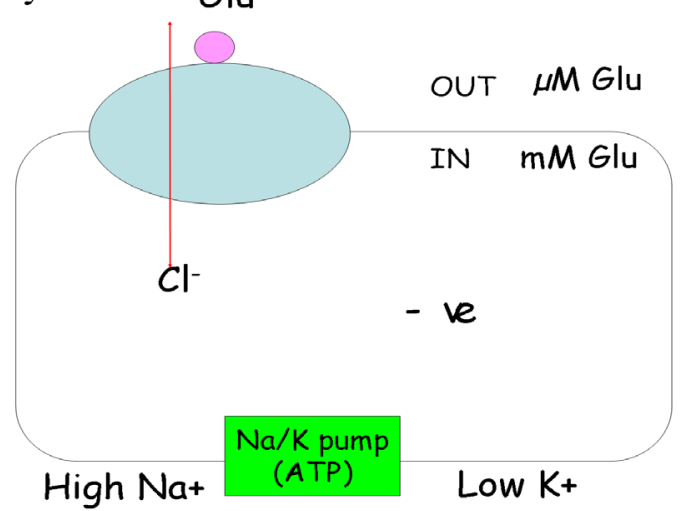

Figure 3. GLAST-1 ion channel and transport functions. Energy for the uptake of glutamate by cells against the concentration gradient and ionic gradient is provided by electrochemical gradients of $\mathrm{Na}^{+}$and $\mathrm{K}^{+}$ (reviewed in Danbolt, 2001). (a) $3 \mathrm{Na}^{+}$ions are cotransported with each glutamate molecule and $\mathrm{K}^{+}$ion is counter-transported resulting in a net positive charge moving into the cell. High extracellular $\mathrm{Na}^{+}$and low extracellular $\mathrm{K}^{+}$concentrations are maintained by the sodium pump. (b) GLAST-1 also exhibits a glutamategated anion conductance that is independent from glutamate transport. co-transported with $3 \mathrm{Na}^{+}$ions and a $\mathrm{K}^{+}$ion is countertransported. If $\mathrm{Na}^{+}$and $\mathrm{K}^{+}$gradients across the cell membrane are reversed then GLAST-1 will release glutamate from the cell. The net positive charge moving into the cell during glutamate uptake may depolarise the cell membrane affecting the cells responses to other signalling pathways including the activation of ionotropic glutamate receptors (Danbolt, 2001).

GLAST-1 also acts as a glutamate gated ion channel, a function that is independent from glutamate transport (Slotboom et al., 2001) requiring a different protein conformation (Kanner and Borre, 2002). Flow of chloride ions through this channel may compensate for membrane potential changes induced by glutamate uptake, modulate activation of glutamate receptors or directly activate intracellular signalling cascades (Danbolt, 2001; Mason and
Huggett, 2002).

The amino acid residues in GLAST-1 that are critical for its function have been mapped. Sodium, potassium and glutamate binding all occur within residues $392-415$ of GLAST-1 and the amino acid motifAAI(V)FIAQ (409-415) is conserved in all eukaryotic and prokaryotic glutamate transporters, indicative of a critical role in transporter function (Seal and Amara, 1999). Tyr-405 and Arg-479 of GLAST-1 are essential for glutamate transport function (Conradt and Stoffel, 1995), residues 442-449 confer chloride permeability (Mitrovic et al., 1998) whereas mutation of Arg-122 or Arg-280 can alter substrate affinity. All of these critical residues are present in GLAST-1a (except for Arg-122), although whether they are similarly oriented, or fulfil the same function in this variant, remains to be determined. However, we have shown that Xenopus oocytes in- 
jected with cRNA encoding GLAST-1a take up radiolabelled glutamate and generate concentration-dependent inward currents on application of glutamate in a manner similar to GLAST-1 (Huggett, Daniels and Mason, unpublished data).

\section{Localisation of GLAST variants in MLO-Y4 osteocytes}

Various stimuli regulate GLAST-1 expression, localisation and activity revealing a complex system in which GLAST variants may alter cell phenotype by modulation of extracellular glutamate concentration, by acting as glutamate gated ion channels, or by activation of intracellular signalling cascades. In glial cells, GLAST-1 expression increases in response to increased extracellular glutamate concentrations. The cell surface expression of GLAST-1 is also rapidly up-regulated in astrocytes in response to increased extracellular glutamate concentrations (Duan et al., 1999). GLAST-1 activity can also be quickly regulated by direct oxidation (Trotti et al., 1997, 1998) or phosphorylation (Conradt and Stoffel, 1997) of the transporter. To determine whether GLAST-1 is regulated in a similar manner in bone cells, we have investigated the subcellular distribution of GLAST-1 and GLAST-1a by transfecting MLOY4 osteocyte-like cells with green fluorescent protein (GFP) -tagged GLAST isoforms. GLAST-1 localised to the plasma membrane whereas GLAST-1a appeared to be expressed within internal vesicles at similar extracellular glutamate concentrations (Huggett et al., 2002). However, low extracellular glutamate concentrations redistributed GLAST-1-GFP into a similar internal expression pattern to GLAST-1a (Huggett et al., 2002). We have also discovered that the relative abundance of GLAST-1 and GLAST1a mRNA varies with extracellular glutamate concentration (Huggett et al., 2002). The effect of extracellular glutamate concentration on GLAST variant localisation and abundance in osteocytes and osteoblasts reveals independent roles for these variants which may be co-ordinated to control glutamate uptake, ion channel or signalling activity.

\section{In vivo evidence for glutamate signalling in bone}

Whilst functional glutamate signalling has been clearly demonstrated in osteoblasts and osteoclasts in vitro, the effects of modulation of glutamate signalling in vivo is unclear. Of the glutamate receptor and transporter knockout mice strains that survive, none have been reported to cause major skeletal abnormalities. However, changes in the gross morphology of the brain of these knockout mice is not always apparent either, and it is the responses of neuronal or glial cells to certain stimuli that reveal the functional significance of each gene. Such detailed analyses of bone cell responses in these knockout animals have not yet been performed. Mice in which NMDA receptor subunits 1 (NMDAR1) or 2B have been deleted do not survive. However, mice that underexpress NMDAR 1 (5-10\% of normal levels) are smaller than littermates expressing normal levels of NMDAR1, which may reflect a disruption in skeletal development (Mohn et al., 1999).

Only one study has been published where the bone phenotype was analysed in mice lacking a gene involved in glutamate signalling. In this instance the gene encoding GLAST was disrupted by deletion of exon 6, thus eliminat- ing both GLAST-1 and GLAST-1a expression. These knockout mice reveal no gross skeletal abnormalities and bone lengths at six months appeared to be normal (Gray et al., 2001a). This, along with some in vitro assays that contradicted previous workers findings, (see Skerry et al., 2001, Chenu et al., 2001 and Gray et al., 2001b for discussion of these data) led the authors to conclude that glutamate signalling is not important in bone growth. However, it still remains to be determined whether these animals have a more subtle phenotype reflecting altered responses of bone cells to mechanical stimuli.

Human disease mutations linking to the GLAST-1 locus sometimes include bone abnormalities, but none of these have been directly mapped to the GLAST gene. Bone loss often occurs in human patients and animals where nerve damage has disrupted the normal innervation of the bones (Lerner, 2002). Since nerve fibres containing glutamate (as well as other neurotransmitters) infiltrate cortical and trabecular bone, osteopenia associated with nerve damage may reflect local responses of bone cells to a lack of glutamate release from nerve terminals.

\section{Glutamate and Mechanical Signal Transduction in Bone}

Whilst individual components of glutamate signalling have been shown to be expressed and functional in various types of bone cell, the actual signal that commences an episode of glutamate release remains to be elucidated. The original discovery that GLAST-1 mRNA is regulated in osteocytes in vivo, in response to osteogenic mechanical stimuli, is highly indicative of a role for glutamate signalling in the adaptive response of the skeleton to its mechanical environment. The expression of glutamate receptors and transporters by osteocytes in vivo (Table 1) reveal that they have the potential to respond to glutamate. This is supported by the trafficking of GLAST-1 in MLO-Y4 osteocytes in response to extracellular glutamate concentrations (Huggett et al., 2002).

Ion channels in osteocytes and osteoblasts have been implicated in mechanical signal transduction and represent a mechanism by which physical stimuli can be translated into the biochemical signals associated with mechanotransduction (El Haj et al., 1990, 1999; Rawlinson et al., 1996; Walker et al., 2000; Gu et al., 2001). The first response to mechanical signals that has been detected in osteoblasts is an influx of calcium and increase in intracellular calcium which preceeds nitric oxide release and prostaglandin production (Jones et al., 1991, Hung et al., 1996). Both long-lasting (L-type) voltage-sensitive calcium channels (VSCC) (Ryder and Duncan, 2001; Li et al., 2002) and stretch-sensitive calcium channels (SSCC) are important in mediating this calcium influx. For example, mechanical loading increases intracellular free calcium in osteoblasts via activation of stretch-activated calcium channels (Peake et al. 2000). The mechanically-induced calcium influx induces $c$-fos expression providing a direct link between mechanical stimulus and gene transcription (Peake et al. 2000). 

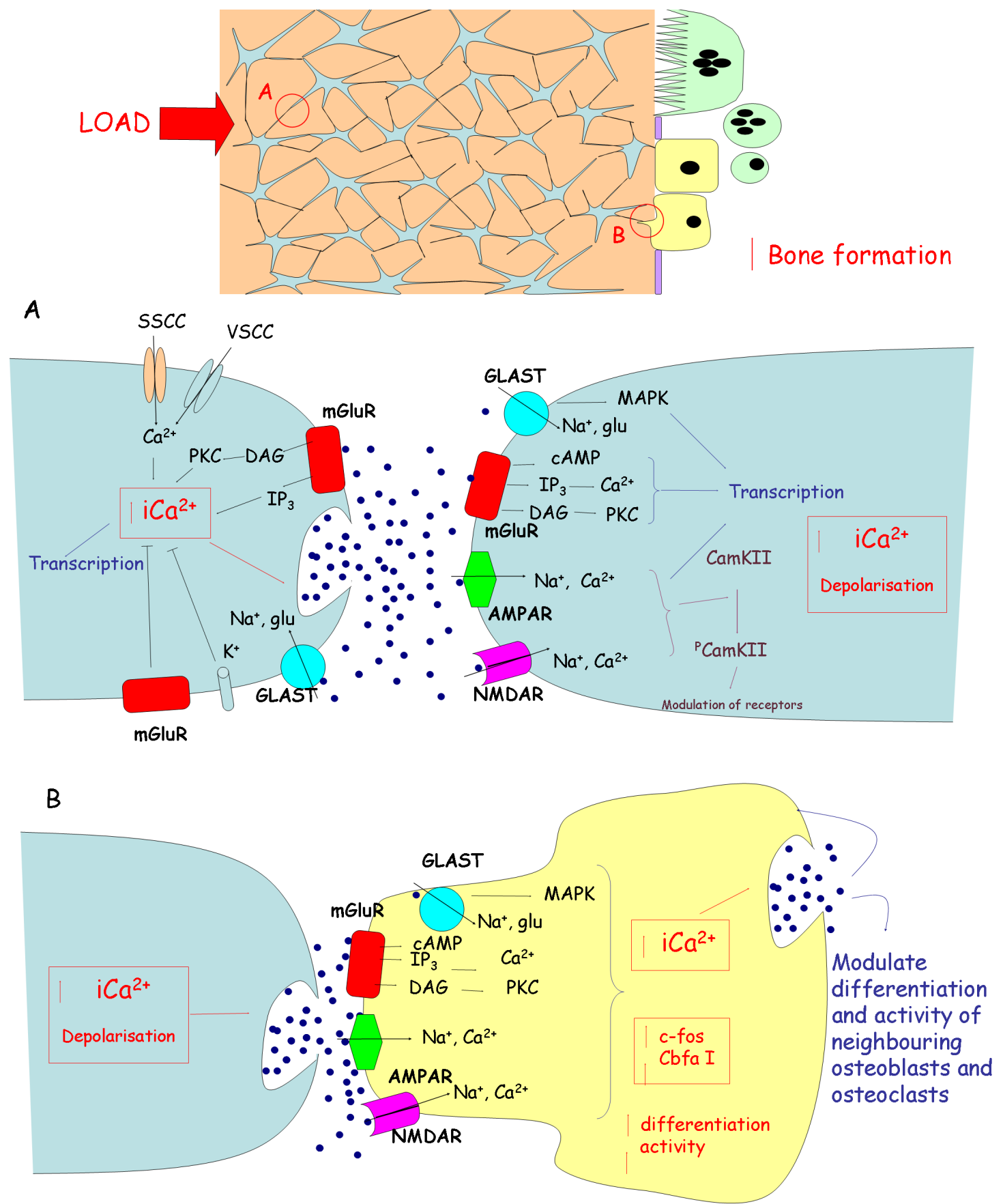

Figure 4. A hypothetical model of glutamate-mediated mechanical signal transduction in bone. In vivo, sitespecific application of osteogenic loading results in increased transcriptional and metabolic activity in osteocytes and local bone formation at surfaces. (A) Influx of calcium via activation of stretch and voltage sensitive calcium channels (SSCC, VSCC) induces glutamate release by exocytosis into junctions with neighbouring osteocytes. Glutamate release is regulated by the activities of metabotropic glutamate receptors (mGluR) and potassium channels. Released glutamate binds to ionotropic receptors (NMDAR, AMPAR) on adjacent osteocytes to induce $\mathrm{Na}^{+}$and $\mathrm{Ca}^{2+}$ influx, and metabotropic receptors (mGluR) to activate G-protein coupled pathways. Glutamate receptor activation influences the transcriptional activity of the osteocyte as well as elevating intracellular calcium (iCa $\left.{ }^{2+}\right)$ to induce glutamate release at the next cell junction and signal propagation. Phosphorylation of CaMKII would alter glutamate receptor responses to subsequent signalling episodes both in osteocytes and osteoblasts at the bone surface. The glutamate transporter GLAST-1 controls extracellular glutamate levels and thus receptor activation, but may also activate MAPK pathways to influence transcription. (B) At the bone surface, glutamate is released at a junction between the osteocyte and preosteoblast. Activation of glutamate receptors on the preosteoblast may cause release of glutamate by exocytosis to activate neighbouring cells in the vicinity (osteoblasts, osteoclasts and their precursors) resulting in a local osteogenic response. Glutamate receptor activation would increase the differentiation and matrix production of osteoblasts via induction of Cbfa I and c-fos. Transcriptional responses may also influence the production of the classic mechanotransduction molecules prostaglandin, nitric oxide and IGF I. 
A hypothetical model depicting mechanically-induced glutamate signal propagation and osteogenesis in bone is shown in figure 4. Mechanical loading opens stretch and voltage sensitive calcium channels (SSCC, VSCC) causing calcium influx and depolarisation of osteocytes. This represents the activating signal that leads to glutamate release by exocytosis. The increased extracellular glutamate activates glutamate receptors in neighbouring osteocytes causing depolarisation, glutamate release by exocytosis and propagation of the glutamate signal to osteoblasts and osteoprogenitors at the bone surface. Influx of calcium via ionotropic glutamate receptors and activation of G-protein coupled pathways through metabotropic glutamate receptors will activate second messengers which may influence transcription and synthesis of classic mechanical signalling molecules in bone such as prostaglandins, nitric oxide and IGF I. Calcium influx either directly through SSCC or via ionotropic glutamate receptors may activate nitric oxide (NO) synthases expressed by osteocytes to cause the rapid increase in NO that has been observed in these cells in response to mechanical strain (Van't Hof and Ralston, 2001). Likewise activation of NO responsive pathways in these cells may influence subsequent glutamate receptor activation. Fast termination of glutamate signals by GLAST-1 mediated glutamate uptake would allow separate signalling episodes to be discriminated. 'Memory' of previous mechanical signalling episodes may be facilitated via modification and redistribution of AMPA glutamate receptors in response to the activation of calciumcalmodulin dependent protein kinase II (CaMKII) in a similar manner to long term potentiation in the CNS (Spencer and Genever, 2003). Indeed, CaMKII activation has been reported to occur in mechanically-loaded osteoblasts and many of the proteins that regulate the localisation and functional properties of glutamate receptors in the post-synaptic membrane are also expressed in osteoblasts (Skerry, 2002). At the bone surface the glutamate signal propagated through osteocytes would activate glutamate receptors on cells in contact with the osteocytes to induce differentiation to mature osteoblasts. Glutamate release by osteoblasts at the bone surface would activate receptors on preosteoclasts and preosteoblasts and contribute to the balanced activity of these cell types.

In this model, the glutamate signal at the bone surface would be moderated by individual osteocyte responses. Thus cAMP-mediated activation of protein kinase A (PKA) and diacylglyerol activation of $\mathrm{PKC}$ result from metabotropic receptor activation and can directly lead to phosphorylation of calcium channels to alter their open probability and channel kinetics (Duncan et al., 1998). Systemic hormones such as parathyroid hormone that bind to receptors activating PKA and PKC pathways would similarly influence the outcome of a mechanical signalling response (Turner et al., 2002). Phosphorylation of CaMKII by activation of AMPA and NMDA receptors would alter the activity of glutamate receptors in subsequent signalling events and modulate responses. This internal processing of the glutamate signal represents the mechanism by which bone cells responses can be modified according to previous signalling episodes. The biochemical changes within each cell that modify ion channel and receptor activity rep- resents a 'memory' that may determine whether a mechanical signal is ultimately osteogenic.

The pathways linking mechanically-induced osteogenesis and glutamate signalling are not yet known and the model in figure 4 is hypothetical. However, it is clear that elucidation of the role of glutamate signalling in mechanotransduction would facilitate its exploitation in bone tissue engineering strategies as well as in the treatment of disorders of the skeleton such as osteoporosis.

\section{The Function of GLAST-1 in Mechanotransduction in Bone}

Until the functional properties of GLAST-1 and GLAST1a in bone cells are determined, the precise role of this transporter in mechanotransduction can only be predicted based on its operation in glial cells. However, we have shown that GLAST-1 is expressed in the plasma membrane of osteocytes and trafficked to the membrane in response to extracellular glutamate concentration (Huggett et al., 2002). GLAST-1 can operate as a glutamate transporter and a glutamate gated ion channel and either of these functions may be important in mechanotransduction in bone. Since glutamate transport by GLAST-1 is driven by electrochemical gradients of $\mathrm{Na}^{+}$and $\mathrm{K}^{+}$across the plasma membrane, any factor that disrupts these gradients may alter the direction of glutamate transport. Disruption of the electrochemical gradient may occur via inactivation of the sodium pump, opening of mechanoresponsive ion channels or the influence of streaming potentials. Osteoblasts and osteocytes possess a range of ion channels $\left(\mathrm{Na}^{+}, \mathrm{Ca}^{2+}\right.$, $\mathrm{K}^{+}, \mathrm{Cl}^{-}$) which are activated by voltage, stretch or second messenger signals. Mechanical activation of osteocyte ion channels may affect the electrochemical gradients across the cell membrane and thus directly alter GLAST-1 activity leading to an alteration in the extracellular glutamate concentration, or even to reversal of the transporter and glutamate release. Alternatively, the ion channel activity of GLAST-1 itself or the depolarisation of cells that results from $\mathrm{Na}^{+}$influx during glutamate uptake by GLAST-1, may be more important in mechanical signal transduction in bone.

Recent reports demonstrating that intracellular interactions of the $\mathrm{N}$ - and C-terminals of glutamate transporters can influence transporter activity and expression provide a new dimension to the function of GLAST-1 in bone (figure 5). Such interactions have been shown to reduce glutamate transport by reducing substrate affinity (Marie and Attwell, 1999; Lin et al., 2001), and are implicated in mediation of MAPK and G-protein/Rho kinase signalling and anchoring of transporters to the actin cytoskeleton (Jackson et al., 2001). The interaction of glutamate transporters with the actin cytoskeleton may represent a mechanism by which mechanical signals can directly influence glutamate transporter activity. Identification of proteins involved in the Cterminal interactions of GLAST-1 may allow them to be targeted to facilitate subtle variation in GLAST-1 activity. The GLAST-1a variant is of particular relevance to these studies as we have predicted its C-terminal is extracellular and thus not available for such interactions 


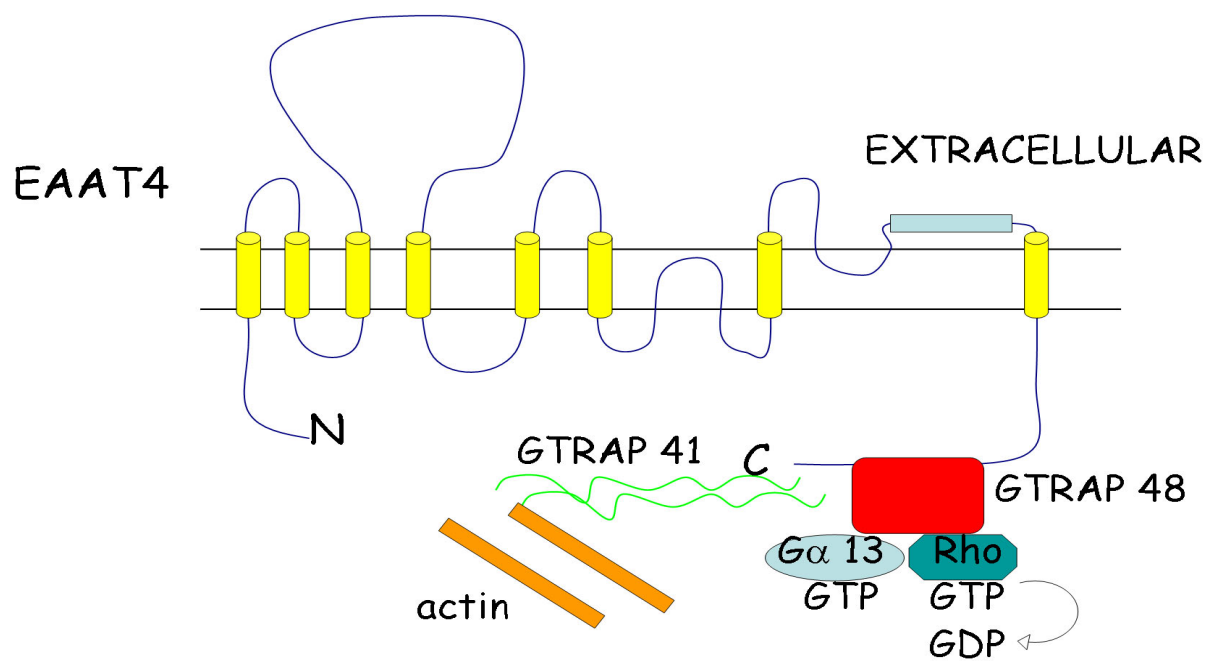

ADAPTED FROM JACKSON ET AL. 2001

\begin{tabular}{|c|c|c|c|c|c|}
\hline Transporter & $\begin{array}{l}\text { Interacting } \\
\text { protein }\end{array}$ & $\begin{array}{l}\text { N or } \mathbf{C} \\
\text { Term }\end{array}$ & $\begin{array}{l}\text { Effect on } \\
\text { glutamate } \\
\text { transport }\end{array}$ & Signalling Pathway & Reference \\
\hline EAAT1 & unidentified & $\mathrm{C}$ & Increase & $\begin{array}{l}\text { MAPKI } \\
\text { Cytoskeleton }\end{array}$ & $\begin{array}{l}\text { Marie and } \\
\text { Attwell } 1999\end{array}$ \\
\hline GLT-1 & Ajuba & $\mathrm{N}$ & none & $\begin{array}{l}\text { MAPKI } \\
\text { Cytoskeleton }\end{array}$ & $\begin{array}{l}\text { Marie et al. } \\
2002\end{array}$ \\
\hline EAAC1 & GTRAP3-18 & $\mathrm{C}$ & Decrease & none & Lin et al. 2001 \\
\hline EAAT4 & GTRAP 41 & $\mathrm{C}$ & Increase & $\begin{array}{l}\text { G-protein/Rho } \\
\text { kinase activation }\end{array}$ & $\begin{array}{l}\text { Jackson et al. } \\
2001\end{array}$ \\
\hline EAAT4 & GTRAP 48 & $\mathrm{C}$ & Increase & actin cytoskeleton & $\begin{array}{l}\text { Jackson et al. } \\
2001\end{array}$ \\
\hline
\end{tabular}

Figure 5. Interactions of glutamate transporters and signalling. A number of proteins that interact with either the $\mathrm{N}$ - or C-terminal sequences of EAATs have been identified. Interactions through these sequences have been implicated in regulating transporter activity and activating intracellular signalling pathways as shown.

How Could Modulation of Glutamate Signalling be Applied to Tissue Engineering?

A successful tissue engineering strategy for bone may be summarised as follows. Firstly, a readily available source of osteoprogenitor cells is required for expansion in culture under conditions that maintain their potential for the osteoblast phenotype. These cells could then be used to generate a bone matrix of suitable composition, strength and cellularity that would ultimately need to integrate with the patients own bone.

If glutamate is a major mediator of mechanical signals in bone cells, modulation of this signalling pathway would allow us to bypass the need to maintain an appropriate mechanical environment for engineered bone. Furthermore, stimulation of this pathway may be exploited as an osteogenic signal to enhance both osteoblast differentiation and bone forming activity. It is envisaged that ultimately modulation of glutamate signalling may be exploited both in vivo, ex vivo and in vitro to increase osteoblast differentiation, extracellular matrix (ECM) formation and maintain responsive osteogenic mechanical signalling pathways in engineered bone.

In vitro expansion of osteoblastic precursor cells is necessary to obtain adequate cell numbers for re-implantation into bone defects. Whilst cells can be directly obtained from bone biopsies a preferable source is bone marrow that contains mesenchymal stem cells (MSC). Culture conditions that enhance differentiation of osteoblasts over the other cell types derived from MSC would enhance the osteogenic potential of the culture. Activation of both NMDA and nonNMDA receptors appear to increase osteoblast differentiation and the non-NMDA receptor has been implicated in switching between osteoblastic and adipogenic lineages (Skerry and Genever, 2001; Taylor, 2002). Thus activation of ionotropic receptors either directly with specific agonists, or indirectly by inactivation of GLAST-1 to increase extracellular glutamate concentration, may be a useful approach to enhance osteoblast differentiation.

Bone matrix formed by the osteoblasts consists of a 
complex array of proteins, proteoglycans and minerals assembled in a regulated structure that is essential to achieve the mechanical properties of bone. Activation of NMDA receptors have been shown to be important in normal expression of bone matrix proteins and appear to be required for normal expression of $C b f a I$, the transcription factor that defines the osteoblast phenotype (Hinoi et al., 2003). Thus controlled activation of these receptors would enhance ECM formation by cultured osteoblasts.

Clearly, cytokines and growth factors can be used to increase the differentiation and activity of osteoblasts in vitro and the question arises as to what advantages that modulation of glutamate signalling may offer above more established methods. One advantage is that there are many levels of control of this signalling cascade, governed by the activities of the various glutamate receptor sub-types and transporters. This may facilitate subtle manipulation of osteoblasts phenotype in vitro but, perhaps more importantly, would also allow osteoblasts to be independently targeted using their precise glutamate receptor and transporter activities either in mixed cultures or in vivo. Another advantage that glutamate signalling has to offer tissue engineering is as a potential means of bypassing the need for normal mechanical loading of bone cells.

In vivo, the mechanical environment of the skeleton has major effects on bone remodelling with increased loading being osteogenic and lack of loading causing bone loss. When implanting engineered bone within scaffolds, it is likely that the mechanical signal transduction pathways have become compromised in the engineered tissue due to disrupted cell/matrix interactions and reduced loading at the defect site. Perhaps the most exciting potential application for glutamate signalling would be to 'prime' the cells to become hyper-responsive to loading. It has been proposed that the regulatory proteins that influence glutamate receptor activation in the CNS may also occur in bone cells providing a mechanism for 'memory' of previous signalling events to regulate mechanical responses (Skerry, 2002; Turner et al., 2002; Spencer and Genever, 2003). Indeed since preliminary studies have reported activation of CaMKII by mechanical loading of osteoblasts (Spencer et al., 2001), mimicking either this activation directly, or the changes in glutamate receptor responses that it is likely to cause (although this remains to be proven in bone cells), may allow a hyper-responsive state to be achieved. If the biochemical processes that alter glutamate receptor activation can be induced artificially, osteoblasts may be primed to respond osteogenically to low levels of mechanical loading and thus increase bone mass in sites of skeletal weakness.

Since glutamate transporters regulate extracellular glutamate concentrations, control of the expression or activity of GLAST-1 in osteoblasts may be used to enhance the osteogenic signal by causing an increase in glutamate receptor activation. Such control may be achieved by targeting GLAST-1 mRNA for degradation using RNA interference (RNAi) or via the use of antibodies, competing peptides or glutamate analogues which prevent glutamate transport. Transfection of osteoblasts with short double stranded RNA molecules complementary to GLAST-1, would target GLAST-1 mRNA for degradation by RNAi, reduce protein expression of the transporter and thus reduce glutamate uptake by bone cells. Antibodies or peptides targeted to the specific regions of GLAST-1 that have been associated with glutamate binding or transport could be released into the bone microenvironment to either prevent binding of glutamate or inhibit transporter activity. All of these methods would inhibit glutamate uptake by bone cells and would be predicted to increase glutamate receptor activation. Since in vivo, GLAST-1 is expressed constitutively by osteocytes and switched on in bone forming osteoblasts (Mason et al., 1997), the effects of GLAST inhibition would be targeted to these cell types. Further refinement of such methods may be achieved by their combination with a gene therapy approach to over-express the specific glutamate receptor subtypes that increase osteoblast activity. Use of an osteoblast-specific promotor such as Cbfa 1 to drive overexpression of glutamate receptor subunits may allow targeting of specific osteogenic pathways in osteoblasts to enhance the efficacy of increased extracellular glutamate levels in vivo.

If the ion channel properties of GLAST-1 are found to be important in osteogenic responses, antagonists to the ion channel and glutamate binding sites may be used. Since ion channel and glutamate transport functions of GLAST1 are independent and result from different protein conformations, reagents targeting each of these properties independently could be developed. The properties of GLAST1a with respect to transport, ion channel and signalling remain to be elucidated and interaction between GLAST variants may add another level of complexity and control to this system.

If $\mathrm{N}$ or C-terminal interactions with GLAST-1 are found to activate intracellular signalling cascades, as is the case for the related transporters GLT-1, EAAC1 and EAAT4, these may also represent targets for modulation of transporter activity or glutamate-mediated signalling cascades. The GLAST-1a variant is of particular relevance to these studies since we have predicted that the C-terminal of GLAST-1a is extracellular and thus unavailable for intracellular interactions.

\section{Concluding Remarks}

This paper has reviewed the evidence that glutamate signalling is important in controlling bone cell phenotype and discussed how modulation of this system may ultimately be of benefit to bone tissue engineering. In order to achieve this goal, dissection of the glutamate signalling pathway including the interactions of glutamate receptors, glutamate transporters, glutamate release mechanisms, ion channels, intracellular regulatory proteins and secondary signalling cascades, within all types of bone cell, is essential. The wealth of knowledge from CNS studies can be usefully applied to ensure that pharmacological targets within this system, which is exquisitely controlled at so many levels, can be exploited to maximum benefit to enhance bone formation and skeletal strength. 


\section{Acknowledgements}

I would like to acknowledge Dr Jim Huggett for his major contribution to the GLAST-1 and GLAST-1a studies and Dr Stephen Daniels for Xenopus oocyte studies and useful discussions. Thanks to Professor Lynda Bonewald for kind provision of MLO-Y4 osteocytes and to Sophie Flood, Dr Sophie Gilbert, Professor Vic Duance and Dr Ken Wann for useful comments on manuscript.

\section{References}

Abu-Amer Y, Teitelbaum SL, Chappel JC, Schlesinger P, Ross FP (1999) Expression and regulation of Rab3 proteins in osteoclasts and their precursors. J Bone Miner Res 14: $1855-1860$.

Barry EL (2000) Expression of mRNAs for the alpha 1 subunit of voltage-gated calcium channels in human osteoblast-like cell lines and in normal human osteoblasts. Calcif Tissue Int. 66: 145-150.

Bhangu PS (2003) 'Pre-synaptic' vesicular glutamate release mechanisms in osteoblasts. J Musculoskel Neuron Interact 3: 17-29.

Bhangu PS, Genever PG, Spencer GJ, Grewal TS, Skerry TM (2001) Evidence for targeted vesicular glutamate exocytosis in osteoblasts. Bone 29: 16-23.

Burr DB, Robling AG, Turner CH (2002) Effects of biomechanical stress on bones in animals. Bone 30: 781786.

Chenu C (2002) Glutamatergic regulation of bone resorption. J Musculoskel Neuron Interact 2: 423-431.

Chenu C, Serre C, Rayanal C, Burt-Pichat B, Delmas P (1998) Glutamate receptors are expressed by bone cells and are involved in bone resorption. Bone 22: 295-299.

Chenu C, Itzstein C, Epinosa L (2001). Absence of evidence is not evidence of absence. Redundancy blocks determination of cause and effect. J Bone Miner Res 16: 17281729.

Conradt M, Stoffel W (1995) Functional analysis of the high affinity, $\mathrm{Na}^{+}$-dependent glutamate transporter GLAST-1 by site-directed mutagenesis. J Biol Chem 270: 25207-25212.

Conradt M, Stoffel W (1997) Inhibition of the highaffinity brain glutamate transporter GLAST-1 via direct phosphorylation. J Neurochem 68: 1244-1251.

Danbolt NC (2001) Glutamate uptake. Prog Neurobiol 65: $1-105$.

Duan S, Anderson CM, Stein BA, Swanson RA (1999) Glutamate induces rapid upregulation of astrocyte glutamate transport and cell-surface expression of GLAST. J Neurosci 19: 10193-10200.

Duncan RC, Akanbi KA, Farach-Carson MC (1998) Calcium signals and calcium channels in osteoblastic cells. Semin Nephrol 18: 178-190.

El Haj AJ, Minter SL, Rawlinson SC, Suswillo R, Lanyon LE (1990) Cellular responses to mechanical loading in vitro. J Bone Miner Res 5: 923-932.

El Haj AJ, Walker LM, Preston MR, Publicover SJ (1999) Mechanotransduction pathways in bone: calcium fluxes and the role of voltage-operated calcium channels.
Med Biol Eng Comput 37: 403-409.

Epsinosa L, Itzstein C, Cheynel H, Delmas P, Chenu C (1999) Active NMDA glutamate receptors are expressed by mammalian osteoclasts. J Physiol 518: 47-53.

Genever PG, Skerry TM (2001) Regulation of spontaneous glutamate release activity in osteoblastic cells and its role in differentiation and survival: evidence for intrinsic glutamatergic signaling in bone. FASEB J 15: 15861588.

Gray C, Marie H, Arora M, Tanaka K, Boyde A, Jones S, Attwell D (2001a) Glutamate does not play a major role in controlling bone growth. J Bone Miner Res 16: $742-$ 749 .

Gray C, Boyde A, Jones S, Attwell D (2001b) The curious incident of the [silent] in the night time. J Bone Miner Res 16: 1731-1732.

Grunewald M, Kanner BI (2000) The accessibility of a novel reentrant loop of the glutamate transporter GLT-1 is restricted by its substrate. J Biol Chem 275: 9684-9689.

$\mathrm{Gu}$ Y, Publicover SJ (2000) Expression of functional metabotropic glutamate receptors in primary cultured rat osteoblasts. J Biol Chem 275: 34252-34259.

Gu Y, Preston MR, El Haj AJ, Howl JD, Publicover SJ (2001) Three types of $\mathrm{K}^{+}$currents in murine osteocyte-like cells (MLO-Y4). Bone 28: 29-37.

Gu Y, Genever PG, Skerry TM, Publicover SJ (2002) The NMDA type glutamate receptors expressed in primary rat osteoblasts have the same electrophysiological characteristics as neuronal receptors. Calcif Tissue Int 70: 194203.

Hillam RA, Skerry TM (1995) Inhibition of bone resorption and stimulation of formation by mechanical loading of the modelling rat ulna in vivo. J Bone Miner Res 10: 683-689.

Hinoi E, Fujimori S, Nakamura Y, Yoneda Y (2001) Group III metabotropic glutamate receptors in rat cultured calvarial osteoblasts. Biochem Biophys Res Commun 281: 341-346.

Hinoi E, Fujimori S, Takarada T, Taniura H, Yoneda Y (2002a) Facilitation of glutamate release by ionotropic glutamate receptors in osteoblasts. Biochem Biophys Res Commun 297: 452-458.

Hinoi E, Fujimori S, Takemori A, Kurabayashi H, Nakamura Y, Yoneda Y (2002b) Demonstration of mRNA for particular AMPA and kainate receptor subunits in immature and mature cultured rat calvarial osteoblasts. Brain Res 943: 112-116.

Hinoi E, Fujimori S, Yoneda Y (2003) Modulation of cellular differentiation by N-methyl-D-aspartate receptors in osteoblasts. FASEB J 17: 1532-1534.

Huggett J, Vaughan-Thomas A, Mason D (2000) The open reading frame of the $\mathrm{Na}^{+}$-dependent glutamate transporter GLAST-1 is expressed in bone and a splice variant of this molecule is expressed in bone and brain. FEBS Lett 485:13-18.

Huggett JF, Mustafa A, O’Neal L, Mason DJ (2002) The glutamate transporter GLAST-1 (EAAT-1) is expressed in the plasma membrane of osteocytes and is responsive to extracellular glutamate concentration. Biochem Soc Trans 30: $890-893$. 
Hung CT, Allen FD, Pollack SR, Brighton CT (1996) Intracellular $\mathrm{Ca}^{2+}$ stores and extracellular $\mathrm{Ca}^{2+}$ are required in the real time $\mathrm{Ca}^{2+}$ response of bone cells experiencing fluid flow. J Biomech 29: 1411-1417.

Itzstein C, Epinosa L, Delmas P, Chenu C (2000) Specific antagonists of NMDA receptors prevent osteoclasts sealing zone formation required for bone resorption. Biochem Biophys Res Commun 268: 201-209.

Itzstein C, Cheynel H, Burt-Pichat B, Merle B, Epinosa L, Delmas P, Chenu C (2001) Molecular identification of NMDA glutamate receptors expressed in bone cells J Cell Biochem 82: 134-144.

Jackson M, Song W, Liu MY, Jin L, Dykes-Hoberg M, Lin CI, Bowers WJ, Federoff HJ, Sternweis PC, Rothstein JD (2001) Modulation of the neuronal glutamate transporter EAAT4 by two interacting proteins. Nature 410: 8993.

Jones DB, Nolte H, Scholubbers JG, Turner E, Veltel D (1991) Biomechanical signal transduction of mechanical strain in osteoblast-like cells. Biomaterials 12: 101-110.

Kanner BI, Borre L (2002) The dual-function glutamate transporters: structure and molecular characterisation of the substrate-binding sites. Biochim Biophys Acta 1555: 92-95.

Klockner U, Storck T, Conradt M, Stoffel W (1993) Electrogenic L-glutamate uptake in Xenopus laevis oocytes expressing a cloned rat brain L-glutamate/L-aspartate transporter (GLAST-1). J Biol Chem 268: 14594-14596.

Laketic-Ljubojevic I, Suva LJ, Maathuis FJ, Sanders D, Skerry TM (1999) Functional characterisation of N-methyl-D-aspartic acid-gated channels in bone cells. Bone 25: 631-637.

Lerner UH (2002) Neuropeptidergic regulation of bone resorption and bone formation. J Muskuloskel Neuron Interact 2: 440-447.

Li J, Burr DB, Turner CH (2002) Suppression of prostaglandin synthesis with NS-398 has different effects on endocortical and periosteal bone formation induced by mechanical loading. Calcif Tissue Int 70: 320-329.

Lin CI, Orlov I, Ruggiero AM, Dykes-Hoberg M, Lee A, Jackson M, Rothstein JD (2001) Modulation of the neuronal glutamate transporter EAAC1 by the interacting protein GTRAP3-18. Nature 410: 84-88.

Marie H, Attwell D (1999) C-terminal interactions modulate the affinity of GLAST glutamate transporters in salamander retinal glial cells. J Physiol 520: 393-397.

Marie H, Billups D, Bedford FK, Dumoulin A, Goyal RK, Longmore GD, Moss SJ, Attwell D (2002) The amino terminus of the glial glutamate transporter GLT-1 interacts with the LIM protein Ajuba. Mol Cell Neurosci 19: 152164.

Mason DJ, Huggett JF (2002) Glutamate transporters in bone. J Musculoskel Neuron Interact 2: 406-414.

Mason DJ, Suva LJ, Genever PG, Patton AJ, Steuckle S, Hillam RA, Skerry TM (1997) Mechanically regulated expression of a neural glutamate transporter in bone: a role for excitatory amino acids as osteotropic agents? Bone 20: 199-205.

Merle B, Itzstein C, Delmas P, Chenu C (2003) NMDA glutamate receptors are expressed by osteoclast precursors and are involved in the regulation of osteoclastogenesis. J Cell Biochem 90: 424-436.

Mitrovic AD, Amara SG, Johnston GA, Vandenberg RJ (1998) Identification of functional domains of the human glutamate transporters EAAT1 and EAAT2. J Biol Chem 273: 14698-14706.

Mohn AR, Gainetdinov RR, Caron MG, Koller BH (1999) Mice with reduced NMDA receptor expression display behaviours related to schizophrenia. Cell 98: 427-439.

Patton AJ, Genever PG, Birch MA, Suva LJ, Skerry TM (1998) Expression of an N-methyl-D-aspartate-type receptor by human and rat osteoblasts and osteoclasts suggest a novel glutamate signalling pathway in bone. Bone 22: 645-649.

Pead MJ, Skerry TM, Lanyon LE (1988a) Direct transformation from quiescence to bone formation in the adult periosteum following a single period of bone loading. $\mathrm{J}$ Bone Miner Res 3: 647-656.

Pead MJ, Suswillo R, Skerry TM, Vedi S, Lanyon LE (1988b) Increased 3H-uridine levels in osteocytes following a single short period of dynamic bone loading in vivo. Calcif Tissue Int 43: 92-96.

Peake MA, Cooling LM, Magnay JL, Thomas PB, El Haj AJ (2000) Cellular responses to mechanical stress selected contribution: Regulatory pathways involved in mechanical induction of c-fos gene expression in bone cells. J Appl Physiol 89:2498-2507.

Peet NM, Grabowski PS, Laketic-Ljubojevic I, Skerry TM (1999) The glutamate receptor antagonist MK801 modulates bone resorption by a mechanism predominantly involving osteoclast differentiation. FASEB J 13: 21792185.

Rawlinson SC, Pitsillides AA, Lanyon LE (1996) Involvement of different ion channels in osteoblasts and osteocytes early responses to mechanical strain. Bone 19: 609-614.

Rubin CT, Lanyon LE (1987) Ostoregulatory nature of mechanical stimuli - function as a determinant for adaptive remodelling in bone. J Orthop Res 3: 647-656.

Ryder KD, Duncan RL (2001) Parathyroid hormone enhances fluid shear-induced $\mathrm{Ca}^{2+}$ signalling in osteoblastic cells through activation of mechanosensitive and voltage sensitive $\mathrm{Ca}^{2+}$ channels. J Bone Miner Res 16: 240248.

Seal RP, Amara SG (1999) Excitatory amino acid transporters: a family in flux. Annu Rev Pharmacol Toxicol 39: 431-456.

Serre C, Farley D, Delmas P, Chenu C (1999) Evidence for a dense and intimate innervation of the bone tissue, including glutamate-containing fibres. Bone 25: 623-629.

Skerry TM (1997) Mechanical loading and bone: what sort of exercise is beneficial to the skeleton? Bone 20: 179181 .

Skerry TM (2002) Neurotransmitters in bone. J Musculoskel Neuron Interact 2: 401-403.

Skerry TM, Genever PG (2001) Glutamate signalling in non-neuronal tissues. Trends Pharmacol Sci 22: 174181.

Skerry TM, Bitensky L, Chayen J, Lanyon LE (1989) Early strain related changes in enzyme activity in osteocytes 
following bone loading in vivo. J Bone Miner Res 4: 783788.

Skerry T, Genever P, Taylor A, Dobson K, Mason D, Suva L (2001) Absence of evidence is not evidence of absence. The shortcomings of the GLAST knockout mouse. J Bone Miner Res 16: 1729-1732.

Slotboom DJ, Konings WN, Lolkema J (2001) The structure of glutamate transporters shows channel-like features. FEBS Lett 492: 183-186.

Spencer GJ, Genever PG (2003) Long-term potentiation in bone - a role for glutamate in strain-induced cellular memory? BMC Cell Biol 4: 9.

Spencer GJ, Grewal TS, Genever PG, Skerry TM (2001) Calcium dependent protein kinase II activity is obligate for bone formation in vitro. J Bone Miner Res 16: OC25 (abstr).

Taylor AF (2002) Functional osteoblastic ionotropic glutamate receptors are a prerequisite for bone formation. J Musculoskel Neuron Interact 2: 415-422.

Torrance AG, Mosley JR, Suswillo RF, Lanyon LE (1994) Noninvasive loading of the rat ulna in vivo induces a strain-related modeling response uncomplicated by trauma or periosteal pressure. Calcif Tissue Int 54: 241-247.

Trotti D, Rizzini BL, Rossi D, Haugeto O, Racagni G, Danbolt NC, Volterra A (1997) Neuronal and glial glutamate transporters possess an $\mathrm{SH}$-based redox regulatory mechanism. Eur J Neurosci 9: 1236-1243.

Trotti D, Danbolt NC, Volterra A (1998) Glutamate transporters are oxidant-vulnerable: a molecular link between oxidative and excitotoxic neurodegeneration? Trends Pharmacol Sci 19: 328-334.

Turner CH, Robling AG, Duncan RL, Burr DB (2002) Do bone cells behave like a neuronal network? Calcif Tissue Int 70: 435-442.

Van't Hof RJ, Ralston SH (2001) Nitric oxide and bone. Immunology 103: 255-261.

Walker LM, Publicover SJ, Preston MR, Said Ahmed MA, El Haj AJ (2000) Calcium-channel activation and matrix protein upregulation in bone cells in response to mechanical strain. J Cell Biochem 79: 648-661.

\section{Discussion with Reviewers}

P.G. Genevar: Many different glutamate receptors have been identified on many different bone cell types and their activation can provoke a variety of cellular effects. Do you consider that manipulation of glutamate transporter function, to modulate extracellular glutamate concentrations, will be sufficiently specific to induce a desired therapeutic effect?

Authors: This is an interesting question and can be approached in two ways, the first assuming that the main function of these molecules is glutamate transport, and the second considering non-transport functions. Assuming that the major role of glutamate transporters in bone is to control extracellular glutamate concentrations, the impact of their manipulation will depend upon their normal distribution and regulation in bone in vivo. Original studies indicated that GLAST-1 is downregulated in osteocytes after mechani- cal loading but up-regulated in bone forming osteoblasts in vivo (Mason et al., 1997). Therefore, artificial downregulation of GLAST-1 at the bone surface is likely to increase activation of glutamate receptors on all of the cell types present. If the effect of this increase could be targeted to osteoblasts by modulation of specific glutamate receptors associated with their osteogenic activity, a greater impact may be achievable. Considering non-transport functions, glutamate dependent activation of ion channels and MAPK pathways in glutamate transporters may ultimately prove to be important in bone. These activities could be artificially manipulated by targeting the appropriate regions of the transporter.

P.G. Genevar: Following your findings on GLAST-1a expression by different osteoblastic and osteocytic cells, is it possible that it is the relative expression levels of GLAST1 and GLAST-1a that determines glutamate handling ability during osteoblast differentiation?

Authors: We certainly believe that the relative expression of GLAST-1 and GLAST-1a are important in the glutamate handling of osteoblasts and osteocytes since the relative abundance of GLAST-1 and GLAST-1a varies in response to extracellular [glutamate] in osteoblasts (Huggett et al., 2002). However, we have not correlated this with osteoblast differentiation. Although GLAST-1a can transport glutamate when expressed in Xenopus oocytes, it does not localise to the plasma membrane, nor traffick in response to extracellular glutamate concentration in the way that GLAST-1 does in MLO-Y4 osteocytes. This suggests at least some functional differences that are likely to reflect the different structures of GLAST-1 and GLAST-1a. It is worth noting that since these variants cannot be distinguished by inhibitors or antibodies and only differ in the presence or absence of $138 \mathrm{bp} / 46$ amino acids, their individual roles in glutamate handling in any cell type has largely been overlooked.

K Itaka: Has there been clear evidence so far of the relationship between the glutamate receptors on the bone cells and the 'memory' function (i.e. priming or hyper-sensitive state)?

Authors: Long term potentiation whereby a long-lasting enhancement in synaptic transmission occurs in neurons has been associated with activation of CAMKII in response to glutamate-gated $\mathrm{Ca}_{2}+$ influx via NMDA receptors. Activation of CaMKII increases subsequent responses to glutamate by altering channel conductance and distribution of AMPA receptors. As such, this biochemical modification represents a 'memory' that alters long term responses. Preliminary studies have shown that CaMKII activation also occurs in mechanically loaded osteoblasts (Spencer et al. 2001). Since, these cells also express functional NMDA and AMPA receptors, it is feasible that mechanically induced activation of CaMKII enhances subsequent responses to glutamate in osteoblasts, representing a potential mechanism for bone cells to have a biochemical 'memory' of their mechanical environment. This would explain why they are so responsive to short periods of defined mechanical stimuli. Whilst this is the only reported experimental evi- 
dence to back up the idea that bone cells could be primed to be hyper-responsive to mechanical stimuli, these ideas could readily be tested as recently proposed by Spencer and Genever (2003).

M. Alini: The author should tell the reader at least some advantages that the modulation of the glutamate signalling will have compared to the present ways of inducing MSC differentiation into osteoblasts, or bone matrix production (for example, the use of growth factors, cytokines bioreactors) for bone tissue engineering.

Authors: This is a fair comment. There are two potential advantages that modulation of glutamate signalling over other cascades may have as outlined below and also added to the paper.

1. Many levels of control - there are different glutamate receptors, which activate different signalling pathways that vary in osteoblasts and osteoclasts. Appropriate targeting of specific receptor subunits would allow osteoblasts and osteoclasts to be influenced independently. Glutamate transporters also influence receptor activation by controlling extracellular glutamate. The effects of manipulation of GLAST in vivo is likely to be targeted to osteocytes and bone forming osteoblasts, the only cell types expressing the transporter.

2. The involvement of glutamate in mechanotransduction in bone (as revealed by the original in vivo experiment) would facilitate priming of bone cells to respond osteogenically in reduced or absent loading. 